\title{
Calculation of Reactions Cross Section for Neutron-Induced Reactions on ${ }^{127}$ I Isotope
}

\author{
Idris Ahmad, Fatima Salman Koki \\ Department of Physics, Bayero University, Kano, Nigeria \\ Email: manidris37@yahoo.com, fskoki.phy@buk.edu.ng
}

How to cite this paper: Ahmad, I. and Koki, F.S. (2017) Calculation of Reactions Cross Section for Neutron-Induced Reactions on ${ }^{127}$ I Isotope. International Journal of Medical Physics, Clinical Engineering and Radiation Oncology, 6, 344-359.

https://doi.org/10.4236/ijmpcero.2017.63031

Received: July 2, 2017

Accepted: August 27, 2017

Published: August 30, 2017

Copyright $\odot 2017$ by authors and Scientific Research Publishing Inc. This work is licensed under the Creative Commons Attribution International License (CC BY 4.0).

http://creativecommons.org/licenses/by/4.0/

\begin{abstract}
In this work, the reaction cross-section for neutron-induced reactions on ${ }^{127} \mathrm{I}$ isotope was calculated using EXIFON code in the energy range of incident particle from $0 \mathrm{MeV}$ to $30 \mathrm{MeV}$. The code is based on an analytical model for statistical multistep direct and multistep compound reactions (SMD/SMC model). In order to see the effect of nuclear structure on cross sections, the calculation was done using nuclear shell structure effect and without considering shell structure effect. Obtained results and statistical analysis showed that shell structure effect does not give significant changes to the cross-section at considered energy ranges. This shows that EXIFON code is a good tool for investigation of nuclear reaction cross section and is useful in the production of the radioisotopes of Iodine, Antimony and tellurium of high purity and in an efficient manner using cyclotron or nuclear reactors, these isotopes have potential application for field of medical science especially for diagnostics and therapeutic purposes.
\end{abstract}

\section{Keywords}

Nuclear Reaction, Cross-Section, Excitation Function, Radioisotope, Statistical Multistep Reaction, Nuclear Model

\section{Introduction}

The artificially produced radioactive isotopes are important for many different applications [1]. Radioactive isotopes play an important role in the field of medical science in terms of beneficial applications in both diagnosis and therapy purposes [2].

In radioisotope production programs, nuclear reactions data are mainly needed for optimization of production routes [3].

At present day, radioisotope production for nuclear medicine is important because of its common use in tomography devices. Both single photon emissions 
computed tomography (SPECT) and positron emission tomography (PET) are used for diagnosis in nuclear medicine. In particular, the radionuclide of iodine is used for these purposes. Therefore, this radionuclide plays an important role in medical applications and research. For example, Gamma-emitted short-lived ${ }^{123} \mathrm{I}$ and long live ${ }^{124} \mathrm{I}$ [1] isotopes can be used as the diagnostic image in SPECT and PET. Besides, the ${ }^{124} \mathrm{I}$ allows for studying of important organs such as brain and heart [2]. The long-lived ${ }^{125}$ I isotope is used as a source for internal radiotherapy, bone dosimetry and a biological tracer [3]. Another iodine radionuclide ${ }^{122} \mathrm{I}$ is a very short-lived isotope and used in PET for brain blood-flow studies [4].

For the last 50 years, the International Atomic Energy Agency (IAEA) Nuclear Data Section (NDS) has been collating, compiling and reviewing nuclear data in a collection of databases and publications, aim of making these data available to a global audience to create an awareness of the wide-ranging data available in support of nuclear-related applications [4] [5] [6]. Nuclear reaction by neutron interactions on bismuth-208 was studied for the production of lead isotopes and thallium isotopes [7].

Today, the nuclear databases are accessible online through the website provided by the IAEA Nuclear Data Section (NDS). This site offers access to tens of thousands of nuclear data sets that can be used for research, innovation, development and dissemination. By such materials and files, the authors conducted the calculation on the reaction cross-section for neutron-induced reactions on ${ }^{127}$ I isotope.

\section{Theoretical Background}

Over the years, the concept of statistical multistep processes has become more and more important for the understanding of nuclear reaction mechanism, especially above $20 \mathrm{MeV}$. An analytical model for both statistical multistep direct (SMD) and statistical multistep compound (SMD) processes was applied for describing nuclear reactions up to $30 \mathrm{MeV}$. This can be generalized in several respects:

The extension to higher energies is performed including s-step direct processes for $s=1$ up to 5 .

The same residual interaction is used for computing both formation and decay of the compound nucleus within SMC as well as SMD processes. Thus, there is no reference to the optical model (OM) reaction cross section. The OM cross section for charged particles was used to simulate coulomb effects in the threshold region only [5].

$\alpha$ and $\gamma$-Processes are included Spin-isospin conservation during the two-body collision is considered.

The calculation of Multiple Particle Emission (MPE) is generalized. Up to three decays of the compound nucleus are considered.

This model is formulated in detail for predicting emission spectra for neutrons, protons, alphas and photons including equilibrium, pre-equilibrium, di- 
rect as well as MPE processes in a consistent way.

Calculations are performed with one physical parameter set for several nuclei, several energies, and several reaction types.

\subsection{Statistical Multistep Reaction}

Statistical multistep models are very successful in describing nuclear reactions at energies up to about $100 \mathrm{MeV}$. These models enable the description of direct, pre-equilibrium, and equilibrium processes in a consistent way for a wide mass number range and various reaction channels, e.g. neutrons, protons, alpha, and gamma particles.

The application of a statistical multistep model to heavy nuclei requires the consideration of fission as a competing process to particle and "gamma-ray" emissions. Therefore, statistical multistep models should be extended to the fission channel.

In the statistical multistep model, the total emission spectrum of the process $(a, x b)$ is divided into three main parts [8] [9],

$$
\frac{\mathrm{d} \sigma_{a, x b}\left(E_{a}\right)}{\mathrm{d} E_{b}}=\frac{\mathrm{d} \sigma_{a, b}^{\mathrm{SMD}}\left(E_{a}\right)}{\mathrm{d} E_{b}}+\frac{\mathrm{d} \sigma_{a, b}^{\mathrm{SMC}}\left(E_{a}\right)}{\mathrm{d} E_{b}}+\frac{\mathrm{d} \sigma_{a, x b}^{\mathrm{MPE}}\left(E_{a}\right)}{\mathrm{d} E_{b}}
$$

The first term on the right hand side of Equation (2.1) represents the statistical multistep direct (SMD) part which contains from single-step up to five-step contributions. The second term represents the statistical multistep compound (SMC) emission which is based on a master equation. Both terms together (SMD + SMC) represents the first-chance emission process [5] [7] [10]. The last term of Equation (2.1) represents the multiple particle emission (MPE) reaction which includes the second-chance, third-chance emissions, etc. These terms are summarized below:

$$
\frac{\mathrm{d} \sigma_{a, x b}^{\mathrm{MPE}}\left(E_{a}\right)}{\mathrm{d} E_{b}}=\sum_{c} \frac{\mathrm{d} \sigma_{a, c b}\left(E_{a}\right)}{\mathrm{d} E_{b}}+\sum_{c, d} \frac{\mathrm{d} \sigma_{a, c d b}\left(E_{a}\right)}{\mathrm{d} E_{b}}+\cdots
$$

\subsection{Activation Cross-Sections}

The following relations between the optical model (OM) reaction Cross-section and the energy-integrated partial Cross-sections should be satisfied (at each incident energy $\left(E_{a}\right)$ )

$$
\begin{gathered}
\sigma_{a}^{\mathrm{OM}}=\sum_{b} \sigma_{a, b} \\
\sigma_{a, b}=\sum_{c} \sigma_{a, c b} \text { and } \sigma_{a, c b}=\sum_{d} \sigma_{a, c d b}
\end{gathered}
$$

with $\sigma_{a, b}=\sigma_{a, b}^{\mathrm{SMD}}+\sigma_{a, b}^{\mathrm{SMC}}$ the total first-chance emission, in this context, activation Cross-sections are given by

$$
\begin{gathered}
\sigma_{a, b \gamma}=\sigma_{a, b}-\sum_{c \neq \gamma} \sigma_{a, c b} \\
\sigma_{a, c b \gamma}=\sigma_{a, c b}-\sum_{d \neq \gamma} \sigma_{a, c b d}
\end{gathered}
$$


where $b, c, d \neq \gamma$

For example, the $(n, p)$-activation Cross-sections have the form

$$
\sigma_{a, p \gamma}=\sigma_{n, p}-\sigma_{n, p n}-\sigma_{n, 2 p}-\sigma_{n, p \alpha}
$$

The SMD Cross-section is a sum over s-step direct processes given by: [11]

$$
\frac{\mathrm{d} \sigma_{a, b}^{S M D}\left(E_{a}\right)}{\mathrm{d} E_{b}}=\sum_{s=1} \frac{\mathrm{d} \sigma_{a, b}^{s}\left(E_{a}\right)}{\mathrm{d} E_{b}}
$$

The SMD Cross-section has the form

$$
\frac{\mathrm{d} \sigma_{a, b}^{\mathrm{SMC}}\left(E_{a}\right)}{\mathrm{d} E_{b}}=\sigma_{a}^{S M C}\left(E_{a}\right) \sum_{N=N_{0}}^{N^{I}} \frac{\tau_{N}(E)}{\hbar} \sum_{(\Delta V)} \Gamma_{N, b}^{(\Delta V)}\left(E, E_{b}\right) \uparrow
$$

where $\tau_{N}$ satisfies the time-integrated master equation

$$
-\hbar \delta_{N N_{0}}=\Gamma_{N-2}^{(+)}(E) \downarrow \tau_{N-2}(E)+\Gamma_{N+2}^{(-)}(E) \downarrow \tau_{N+2}(E)-\Gamma_{N}(E) \tau_{N}(E)
$$

and

$$
\Gamma_{N}^{(\Delta v)}(E) \downarrow=2 \pi I_{S S}^{2} \rho_{N}^{(\Delta v)}(E)
$$

The multiple particle emission is expressed as:

$$
\frac{\mathrm{d} \sigma_{a, x b}^{\mathrm{MPE}}\left(E_{a}\right)}{\mathrm{d} E_{b}}=\sum_{c} \frac{\mathrm{d} \sigma_{a, c b}\left(E_{a}\right)}{\mathrm{d} E_{b}}+\sum_{c d} \frac{\mathrm{d} \sigma_{a, c d b}\left(E_{a}\right)}{\mathrm{d} E_{b}}+\cdots
$$

To keep the model tractable, a simple two-body interaction is assumed: [5]

$$
I\left(r_{1}, r_{2}\right)=-4 \pi \frac{F_{0}}{A}\left[\chi_{n l}(R)\right]^{-4} \delta\left(r_{1}-r_{2}\right) \delta\left(r_{1}-R\right)
$$

$F_{0}=27.5 \mathrm{MeV}$ taken from nuclear structure considerations [11].

The factor $\left[\chi_{n l}(R)\right]^{-4}$ contains the wave function at the nuclear radius $R=r_{0} A^{1 / 3}$.

The single-particle state density of particles $C=n, p, \alpha$ with mass $\mu_{c}$ is given by

$$
\begin{aligned}
\rho\left(E_{c}\right) & =\frac{4 \pi V \mu_{c}\left(2 \mu_{c} E_{c}\right)^{1 / 2}}{(2 \pi \hbar)} \\
& =\left(4.48 \times 10^{-3} \mathrm{fm}^{-3} \cdot \mathrm{MeV}^{-3 / 2}\right) r_{0}^{3} A E_{C}^{1 / 2}
\end{aligned}
$$

where $V=\frac{4 \pi R^{3}}{3}$ is equal to the nuclear volume [9].

The single-particle state density of bound particles (at Fermi energy) is then defined by

$$
g=4 \rho\left(E_{F}\right)
$$

where factor 4 considers the spin and isospin degeneracy

\section{Methodology}

EXIFON code is a nuclear reaction software which provides a continuous and smooth description of nuclear reactions over a wide energy and mass range which is based on an analytical model for statistical multistep direct and multis- 
tep compound reactions (SMD/SMC model). It predicts emission spectra, angular distributions, and activation Cross-sections for neutrons, protons, alpha particles, and photons. Multiple particle emissions are considered for up to three decays of the compound system. EXIFON is a fast, easy-to-handle code which predicts Cross-sections from one global parameter set. The only adjustable quantity is the pairing shift. The INPEXI code creates input files for EXIFON2.0 from mass and shell-correction tables. The MAKE6 code transforms EXIFON output into an ENDF-6 format file [9].

The model is based on random matrix physics with the use of the Green's function formalism [12] [13]. All calculations are performed without any free parameters. Results were presented for bombarding energies below $30 \mathrm{MeV}$ [14] [15].

\subsection{Procedure}

\subsubsection{Nuclear Model Calculations}

Theoretical calculations of Cross-section were performed by nuclear model code EXIFON the program was run and the input and output directory were defined, and then the target nucleus is specified. The incident particle and target nucleus were selected and excitation function in the general options section for this calculation was chooses.

The number of incident energy was specified followed by the first incident energy, and then the incident energy step is also specified. The Cross-section correspond to each particular energy was obtained.

The output data (OUTEXI) for the calculation was then stored in the set output directory. Also, DAT file name is stored in the set output directory.

Secondly, the option without shell effect is also used for each target nucleus, also an output data (OUTEXI) for the calculation is then stored in the set output directory. Also, DAT file is stored in the set output directory.

\subsubsection{Shell Structure Effects}

The shell structure effects are considered in SMC processes. Under such a situation, the single-particle state density g, in Equation (2.18) is multiplied by the factors

$$
\left(1+\frac{\delta W}{E_{X}}\left[1-\exp \left(-\gamma E_{X}\right)\right]\right)
$$

With $\gamma=0.05 \mathrm{MeV}^{-1}$ and $\delta W$ as the shell correction energy taken from tables [16]. The quantity $E_{X}=E$ or $U$ denotes the excitation energy of the composite or residual systems respectively.

The calculations in this study were performed with $(\delta W \neq 0)$ and without $(\delta W=0)$ shell corrections.

\section{Results and Discursions}

\subsection{Results}

The calculated cross-section data for neutron-induced reactions on ${ }^{127} \mathrm{I}$ are given 
in Table 1 and Table 2.

The calculations in which the shell correction was taken into consideration are denoted by "With" on the graph's legend, while those without the shell correction effects are denoted by "Without".

Table 1. Cross section (mb) obtain without shell structure effect of I-127 interactions with neutron particle at different energies $(\mathrm{MeV})$.

\begin{tabular}{|c|c|c|c|c|c|c|c|c|c|c|c|c|c|c|c|c|}
\hline Energy & $(\mathrm{n}, \mathrm{a})$ & $(\mathrm{n}, \mathrm{na})$ & $(\mathrm{n}, \mathrm{ag})$ & $(\mathrm{n}, \mathrm{an})$ & $(\mathrm{n}, \mathrm{g})$ & $(\mathrm{n}, \mathrm{ng})$ & $(\mathrm{n}, \mathrm{pg})$ & $(\mathrm{n}, 2 \mathrm{ng})$ & $(\mathrm{n}, \mathrm{n})$ & $(\mathrm{n}, 2 \mathrm{n})$ & $(\mathrm{n}, \mathrm{pn})$ & $(n, 3 n)$ & $(\mathrm{n}, \mathrm{p})$ & $(\mathrm{n}, \mathrm{np})$ & $(\mathrm{n}, 2 \mathrm{p})$ & $(n, 2 n p)$ \\
\hline 1 & 0 & 0 & 0 & 0 & 1316.9 & 1713.8 & 0 & 0 & 1713.8 & 0 & 0 & 0 & 0 & 0 & 0 & 0 \\
\hline 2 & 0 & 0 & 0 & 0 & 267.4 & 2355.1 & 0 & 0 & 2355.1 & 0 & 0 & 0 & 0 & 0 & 0 & 0 \\
\hline 3 & 0 & 0 & 0 & 0 & 83.1 & 2390.3 & 0 & 0 & 2390.3 & 0 & 0 & 0 & 0 & 0 & 0 & 0 \\
\hline 5 & 0 & 0 & 0 & 0 & 17.8 & 2312.5 & 0 & 0 & 2312.5 & 0 & 0 & 0 & 0 & 0 & 0 & 0 \\
\hline 6 & 0 & 0 & 0 & 0 & 10.5 & 2274.2 & 0 & 0 & 2274.2 & 0 & 0 & 0 & 0 & 0 & 0 & 0 \\
\hline 7 & 0 & 0 & 0 & 0 & 7.1 & 2239.4 & 0.1 & 0 & 2239.4 & 0 & 0 & 0 & 0.1 & 0 & 0 & 0 \\
\hline 8 & 0 & 0 & 0 & 0 & 5.6 & 2207.2 & 0.2 & 0 & 2207.2 & 0 & 0 & 0 & 0.2 & 0 & 0 & 0 \\
\hline 9 & 0.1 & 0 & 0.1 & 0 & 4.8 & 2177 & 0.5 & 0 & 2177 & 0 & 0 & 0 & 0.5 & 0 & 0 & 0 \\
\hline 10 & 0.3 & 0 & 0.3 & 0 & 4.4 & 2130.9 & 1 & 17.5 & 2148.4 & 17.5 & 0 & 0 & 1 & 0 & 0 & 0 \\
\hline 11 & 0.8 & 0 & 0.8 & 0 & 4.1 & 1870.5 & 1.8 & 250.2 & 2120.7 & 250.2 & 0 & 0 & 1.8 & 0 & 0 & 0 \\
\hline 12 & 1.4 & 0 & 1.4 & 0 & 3.8 & 1384.5 & 2.9 & 709 & 2093.4 & 709 & 0 & 0 & 2.9 & 0 & 0 & 0 \\
\hline 13 & 2.4 & 0 & 2.4 & 0 & 3.7 & 954.4 & 4.5 & 1111.9 & 2066.4 & 1111.9 & 0 & 0 & 4.5 & 0 & 0 & 0 \\
\hline 14 & 3.6 & 0 & 3.6 & 0 & 3.6 & 674.2 & 6.5 & 1365.1 & 2039.3 & 1365.1 & 0 & 0 & 6.5 & 0 & 0 & 0 \\
\hline 15 & 5 & 0 & 5 & 0 & 3.4 & 516.2 & 8.7 & 1495.9 & 2012 & 1495.9 & 0.3 & 0 & 9 & 0 & 0 & 0 \\
\hline 16 & 6.6 & 0 & 6.6 & 0 & 3.4 & 425.2 & 11 & 1559.4 & 1984.6 & 1559.4 & 0.9 & 0 & 11.9 & 0 & 0 & 0 \\
\hline 18 & 10 & 0 & 9.1 & 0.9 & 3.2 & 343.5 & 15.7 & 1582.9 & 1929.4 & 1585.7 & 3.3 & 2.8 & 19 & 0.2 & 0 & 0 \\
\hline 19 & 11.7 & 0 & 10 & 1.7 & 3.2 & 323.6 & 17.9 & 1341.6 & 1901.7 & 1577.8 & 5.1 & 236.2 & 23.1 & 0.3 & 0 & 0 \\
\hline 20 & 13.4 & 0.1 & 10.7 & 2.7 & 3.2 & 309.1 & 19.9 & 816.6 & 1873.9 & 1564.2 & 7.5 & 747.7 & 27.4 & 0.5 & 0 & 0 \\
\hline 21 & 15.1 & 0.2 & 11.2 & 3.9 & 3.1 & 297.6 & 21.6 & 419.1 & 1846.1 & 1547.7 & 10.4 & 1128.6 & 32 & 0.7 & 0 & 0 \\
\hline 22 & 16.7 & 0.3 & 11.4 & 5.3 & 3.1 & 287.7 & 22.9 & 205.1 & 1818.4 & 1529.5 & 13.8 & 1324.4 & 36.7 & 1 & 0 & 0 \\
\hline 23 & 18.2 & 0.4 & 11.4 & 6.8 & 3.1 & 278.8 & 24.4 & 101.6 & 1790.7 & 1510.3 & 17.2 & 1408.6 & 41.6 & 1.3 & 0 & 0 \\
\hline 24 & 19.7 & 0.6 & 11.3 & 8.4 & 3 & 270.5 & 25.4 & 52.8 & 1763.1 & 1490.4 & 21.3 & 1437.5 & 46.7 & 1.6 & 0 & 0.1 \\
\hline 25 & 21.1 & 0.8 & 11.1 & 10 & 3 & 262.8 & 26.1 & 29.5 & 1735.6 & 1470 & 25.7 & 1440.3 & 51.8 & 2 & 0 & 0.1 \\
\hline 26 & 22.4 & 1.1 & 10.8 & 11.6 & 3 & 253 & 26.7 & 18.1 & 1708.1 & 1451.6 & 30.3 & 1433.2 & 57 & 2.4 & 0 & 0.3 \\
\hline 27 & 23.7 & 1.4 & 10.5 & 13.2 & 3 & 246.3 & 27.2 & 12 & 1680.8 & 1430.3 & 35 & 1417.7 & 62.3 & 2.9 & 0 & 0.5 \\
\hline 28 & 24.8 & 1.7 & 10.1 & 14.7 & 2.9 & 239.6 & 27.6 & 8.6 & 1653.6 & 1408.9 & 40 & 1399.4 & 67.6 & 3.4 & 0 & 0.8 \\
\hline 29 & 25.9 & 2 & 9.7 & 16.2 & 2.9 & 233.2 & 27.9 & 6.5 & 1626.5 & 1387.4 & 45.1 & 1379.5 & 73 & 3.9 & 0 & 1.1 \\
\hline 30 & 26.8 & 2.4 & 9.3 & 17.5 & 2.9 & 227.1 & 28.1 & 5.2 & 1599.5 & 1365.6 & 50.3 & 1358.5 & 78.4 & 4.4 & 0 & 1.6 \\
\hline
\end{tabular}


Table 2. Cross section $(\mathrm{mb})$ obtain with shell structure effect of I-127 interactions with neutron particle at different energies $(\mathrm{MeV})$.

\begin{tabular}{|c|c|c|c|c|c|c|c|c|c|c|c|c|c|c|c|c|}
\hline Energy & $(\mathrm{n}, \mathrm{a})$ & $(\mathrm{n}, \mathrm{na})$ & (n, ag) & $(\mathrm{n}$, an $)$ & $(\mathrm{n}, \mathrm{g})$ & $(\mathrm{n}, \mathrm{ng})$ & $(\mathrm{n}, \mathrm{pg})$ & $(\mathrm{n}, 2 \mathrm{ng})$ & $(\mathrm{n}, \mathrm{n})$ & $(\mathrm{n}, 2 \mathrm{n})$ & $(\mathrm{n}, \mathrm{pn})$ & $(n, 3 n)$ & $(n, p)$ & $(\mathrm{n}, \mathrm{np})$ & $(\mathrm{n}, 2 \mathrm{p})$ & $(\mathrm{n}, 2 \mathrm{np})$ \\
\hline 1 & 0 & 0 & 0 & 0 & 1208 & 1822.6 & 0 & 0 & 1822.6 & 0 & 0 & 0 & 0 & 0 & 0 & 0 \\
\hline 2 & 0 & 0 & 0 & 0 & 240.5 & 2382.1 & 0 & 0 & 2382.1 & 0 & 0 & 0 & 0 & 0 & 0 & 0 \\
\hline 3 & 0 & 0 & 0 & 0 & 75.4 & 2398 & 0 & 0 & 2398 & 0 & 0 & 0 & 0 & 0 & 0 & 0 \\
\hline 4 & 0 & 0 & 0 & 0 & 31.8 & 2357.1 & 0 & 0 & 2357.1 & 0 & 0 & 0 & 0 & 0 & 0 & 0 \\
\hline 5 & 0 & 0 & 0 & 0 & 16.5 & 2313.9 & 0 & 0 & 2313.9 & 0 & 0 & 0 & 0 & 0 & 0 & 0 \\
\hline 6 & 0 & 0 & 0 & 0 & 9.8 & 2274.9 & 0 & 0 & 2274.9 & 0 & 0 & 0 & 0 & 0 & 0 & 0 \\
\hline 7 & 0 & 0 & 0 & 0 & 6.7 & 2239.8 & 0.1 & 0 & 2239.8 & 0 & 0 & 0 & 0.1 & 0 & 0 & 0 \\
\hline 8 & 0 & 0 & 0 & 0 & 5.3 & 2207.4 & 0.2 & 0 & 2207.4 & 0 & 0 & 0 & 0.2 & 0 & 0 & 0 \\
\hline 10 & 0.3 & 0 & 0.3 & 0 & 4.2 & 2131 & 1.1 & 17.4 & 2148.4 & 17.4 & 0 & 0 & 1.1 & 0 & 0 & 0 \\
\hline 11 & 0.8 & 0 & 0.8 & 0 & 4 & 1877.9 & 1.9 & 242.7 & 2120.6 & 242.7 & 0 & 0 & 1.9 & 0 & 0 & 0 \\
\hline 12 & 1.5 & 0 & 1.5 & 0 & 3.8 & 1403.8 & 3.1 & 689.6 & 2093.3 & 689.6 & 0 & 0 & 3.1 & 0 & 0 & 0 \\
\hline 13 & 2.4 & 0 & 2.4 & 0 & 3.6 & 976.4 & 4.7 & 1089.7 & 2066.2 & 1089.7 & 0 & 0 & 4.7 & 0 & 0 & 0 \\
\hline 14 & 3.6 & 0 & 3.6 & 0 & 3.5 & 692.7 & 6.8 & 1346.3 & 2039 & 1346.3 & 0 & 0 & 6.8 & 0 & 0 & 0 \\
\hline 15 & 5.1 & 0 & 5.1 & 0 & 3.4 & 530.2 & 9.1 & 1481.5 & 2011.7 & 1481.5 & 0.3 & 0 & 9.3 & 0 & 0 & 0 \\
\hline 16 & 6.7 & 0 & 6.6 & 0 & 3.3 & 435.1 & 11.4 & 1549.1 & 1984.2 & 1549.1 & 0.9 & 0 & 12.3 & 0 & 0 & 0 \\
\hline 17 & 8.3 & 0 & 8 & 0.3 & 3.3 & 381 & 13.7 & 1575.4 & 1956.6 & 1575.4 & 2 & 0 & 15.8 & 0.1 & 0 & 0 \\
\hline 18 & 10 & 0 & 9.1 & 0.9 & 3.2 & 348.6 & 16 & 1576.1 & 1928.8 & 1580 & 3.5 & 3.9 & 19.6 & 0.2 & 0 & 0 \\
\hline 20 & 13.4 & 0.1 & 10.7 & 2.7 & 3.1 & 312.3 & 20.2 & 760.4 & 1873.1 & 1560.2 & 8 & 799.8 & 28.2 & 0.6 & 0 & 0 \\
\hline 21 & 15.1 & 0.2 & 11.2 & 3.9 & 3.1 & 300.2 & 21.9 & 383.1 & 1845.3 & 1544 & 11 & 1160.9 & 32.8 & 0.9 & 0 & 0 \\
\hline 22 & 16.7 & 0.3 & 11.4 & 5.3 & 3.1 & 290 & 23.2 & 185.4 & 1817.5 & 1525.9 & 14.4 & 1340.6 & 37.7 & 1.2 & 0 & 0 \\
\hline 23 & 18.3 & 0.5 & 11.4 & 6.8 & 3 & 280.9 & 24.7 & 91.3 & 1789.7 & 1506.8 & 18 & 1415.4 & 42.6 & 1.6 & 0 & 0 \\
\hline 24 & 19.7 & 0.7 & 11.3 & 8.4 & 3 & 272.4 & 25.6 & 47.5 & 1762 & 1486.9 & 22.1 & 1439.3 & 47.7 & 2.1 & 0 & 0.1 \\
\hline 25 & 21.1 & 0.9 & 11.1 & 10.1 & 3 & 264.5 & 26.4 & 26.5 & 1734.4 & 1466.4 & 26.5 & 1439.7 & 52.9 & 2.6 & 0 & 0.2 \\
\hline 26 & 22.5 & 1.2 & 10.8 & 11.7 & 3 & 254.7 & 27 & 16.2 & 1706.9 & 1447.9 & 31.2 & 1431.3 & 58.2 & 3.1 & 0 & 0.3 \\
\hline 27 & 23.7 & 1.5 & 10.4 & 13.3 & 3 & 247.9 & 27.5 & 10.7 & 1679.5 & 1426.4 & 36.1 & 1415 & 63.5 & 3.7 & 0 & 0.6 \\
\hline 28 & 24.8 & 1.8 & 10.1 & 14.8 & 2.9 & 241.2 & 27.8 & 7.7 & 1652.2 & 1404.9 & 41.1 & 1396.1 & 68.9 & 4.3 & 0 & 0.9 \\
\hline 29 & 25.9 & 2.2 & 9.7 & 16.2 & 2.9 & 234.7 & 28.1 & 5.8 & 1625.1 & 1383.3 & 46.2 & 1375.7 & 74.3 & 5 & 0 & 1.4 \\
\hline 30 & 26.8 & 2.6 & 9.3 & 17.6 & 2.9 & 228.5 & 28.3 & 4.6 & 1598.1 & 1361.4 & 51.4 & 1354.4 & 79.8 & 5.6 & 0 & 1.9 \\
\hline
\end{tabular}

\subsection{Excitation Functions}

Excitation function is defined as the graphical plots of cross-section against the energy of the incident particle, it is an important parameter in nuclear data analysis describes the probability that nuclear reactions can occur at particular energy of incident particle. Below are the excitation functions of the reactions. 


\subsection{Discursion}

Neutron on ${ }^{127} \mathbf{I}$

Iodine- 127 is a naturally occurring stable element with $100 \%$ abundance isotope of iodine when neutron particle introduced into its nucleus, the nuclear reaction processes occurred and produced other stable and radioactive elements.

Figure 1 is the knockout reaction in which neutron displaced alpha particle from the nucleus of iodine-127. Figure 2 is a compound nucleus formation of iodine-128 and it emits alpha particle to produce Antimony-124.

Figure 1 and Figure 2 shown the excitation function of the interaction between neutron particle and iodine-127 nucleus for the production of Antimony-124 which is one of the radioisotopes of Antimony, it has a half-life of 60 days 21 minute and decays through beta emission and gamma particle.

Figure 3 and Figure 4 shows the excitation function of the production of Antimony-123, is a stable isotope of Antimony.

Figure 5 shown the compound nucleus formation of iodine-128, is a radioactive isotope of iodine with a half-life of twenty-five (25) minutes, it decays either by $\mathrm{e}^{-}$and $\gamma s$ radiations. The shell correction effect was considered in both two graphs and the results show no significant different observed.

Figure 6 is an inelastic collision between the neutron and the nucleus of iodine-127, the graph shows that cross section decreases with increases in the incident energy and Figure 7 is an elastic collision between neutron and nucleus of iodine-127.

Tellurium-127 is an isotope of Tellurium with a half-life of $9.3 \mathrm{~h}$, it decays by beta emission, Figure 8 and Figure 9 shown the compound nucleus formation of this important isotope. The shell correction effect was considered in both two graphs and the results show no significant different observed.

Iodine-126 is a radioactive isotope of iodine with a half-life of thirteen (13) days, it decays either by $\mathrm{e}^{-}, \mathrm{e}^{+}$and $\gamma s$ radiations. Figure 10 and Figure 11 shown the compound nucleus formation of this important isotope, the shell correction effect was considered in both two graphs and the results show no significant different observed.

Tellurium-126 is a stable isotope of Tellurium which can be produced through the reaction in Figure 12 and Figure 13. Figure 12 shows that no change observed for both reactions with shell effect correction and without shell effect correction. Figure 13 shows that changes were observed in the cross sections with and without shell correction.

Iodine-125 is a radioisotope of iodine with a half-life of 56 days and it decays through K-capture and gamma particle. Figure 14: Excitation function for production iodine- 125 .

Figure 15 is an excitation function for the production of Antimony-126 which is a radioactive isotope of Antimony with a half-life of 9 hour and it decays through beta and gamma particle.

Figure 16 is an excitation function for the production of Tellurium-125 which is a radioactive isotope of Tellurium with a half-life of 58 days and it decays 


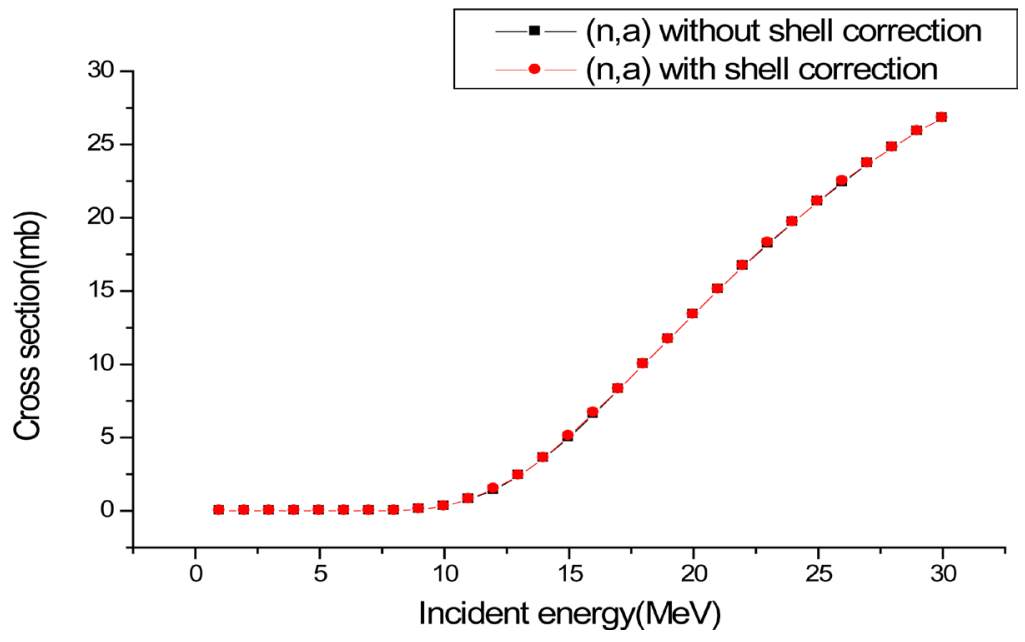

Figure 1. Excitation function of ${ }^{127} I(n, a)$ reaction.

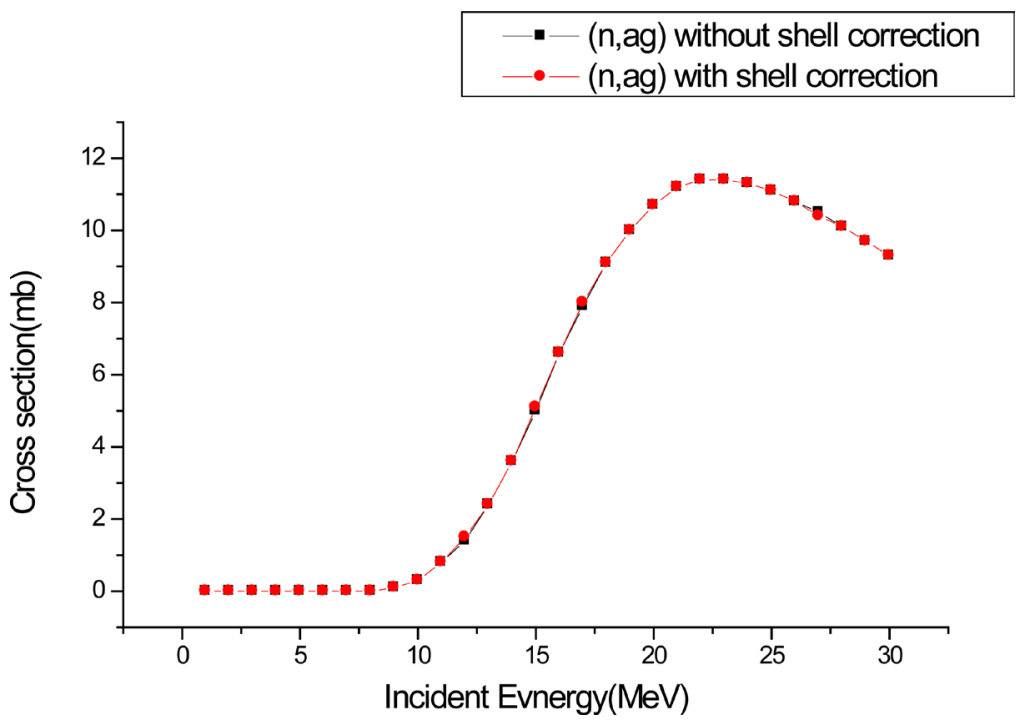

Figure 2. Excitation function of ${ }^{127} I(n, a g)$ reaction.

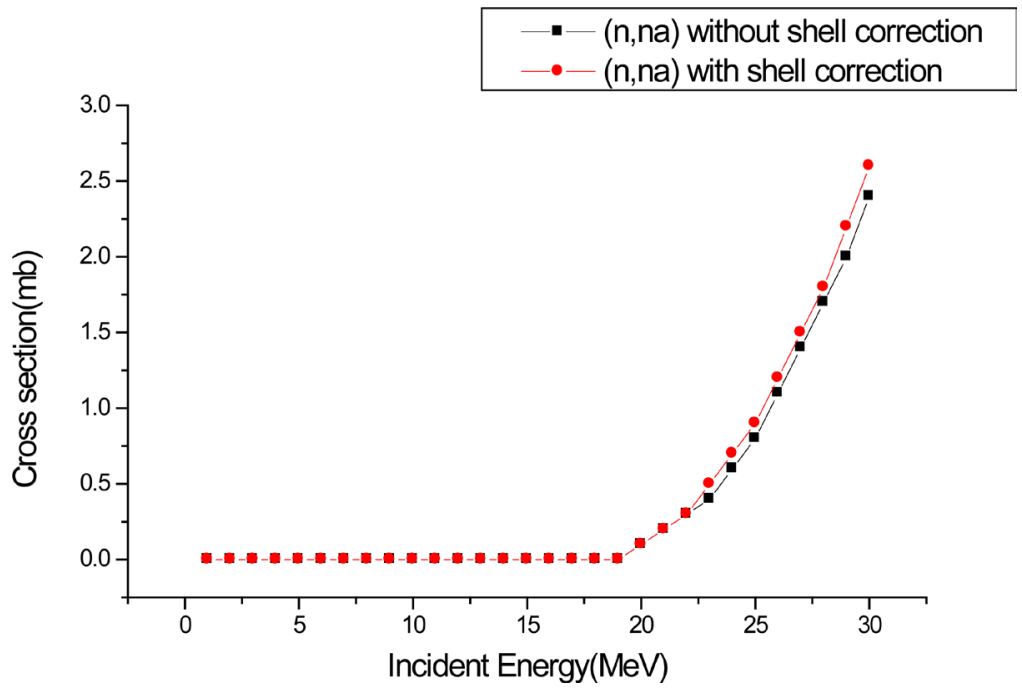

Figure 3. Excitation function of ${ }^{127} I(n, n a)$ reaction. 


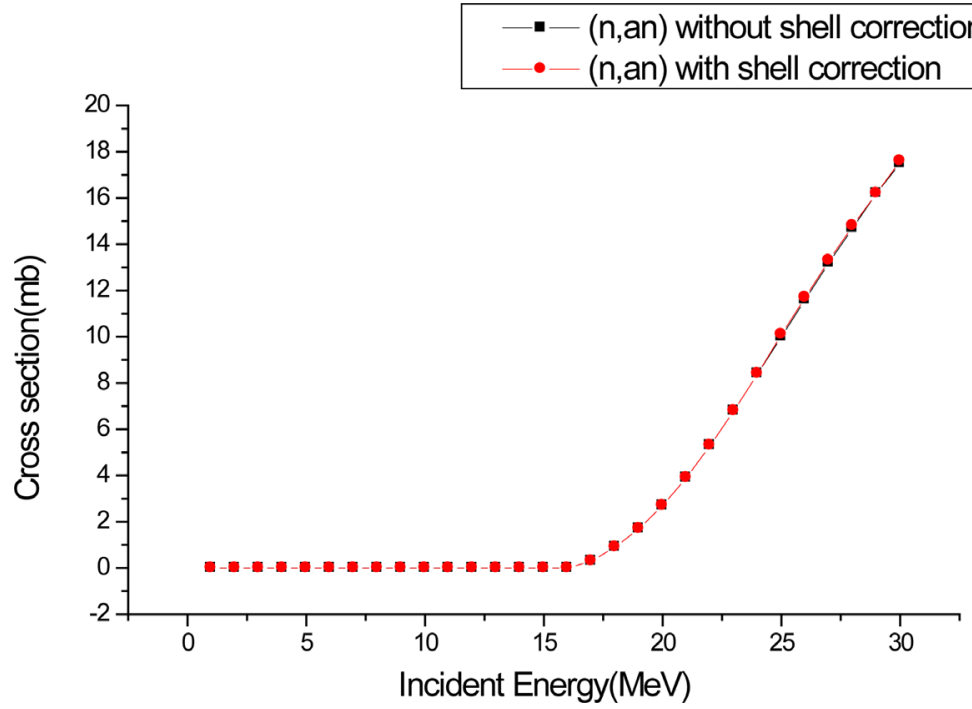

Figure 4. Excitation function of ${ }^{127} I(n, a n)$ reaction.

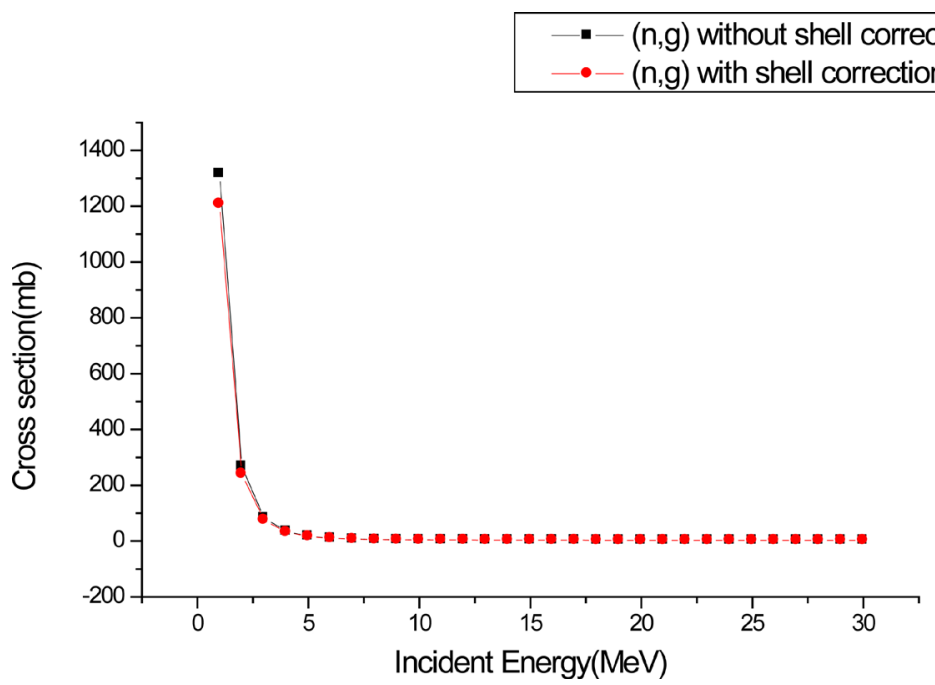

Figure 5. Excitation function of ${ }^{127} I(n, g)$ reaction.

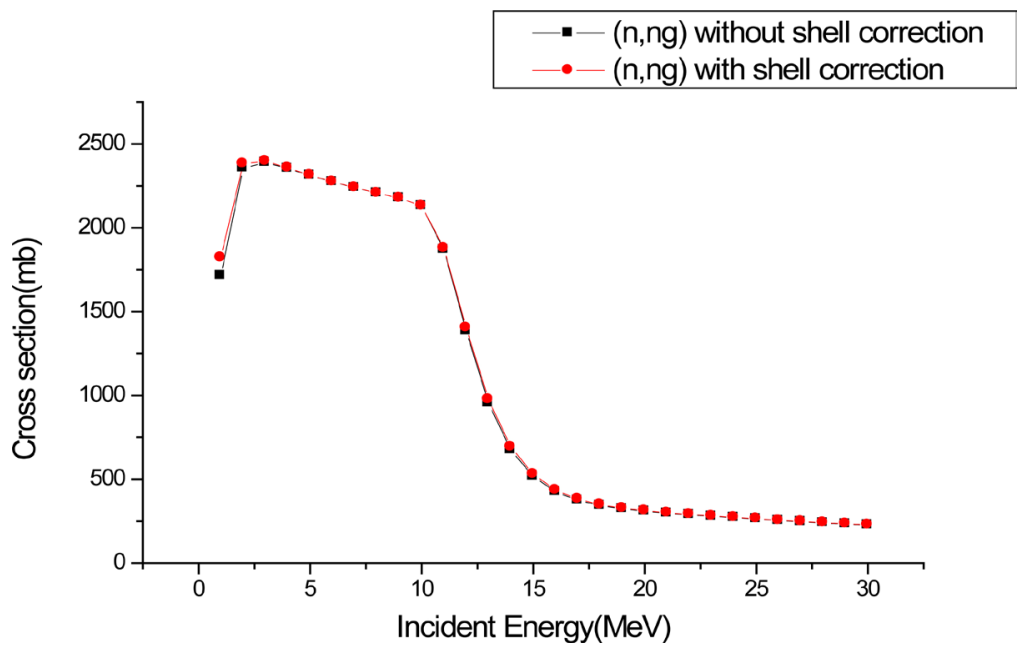

Figure 6. Excitation function of ${ }^{127} I(n, n g)$ reaction. 


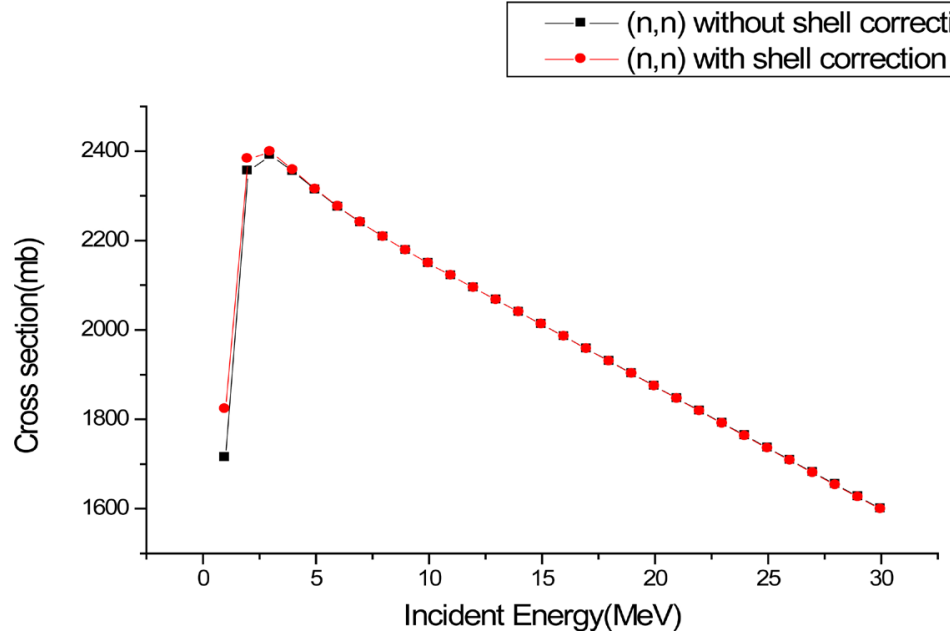

Figure 7. Excitation function of ${ }^{127} I(n, n)$ reaction.

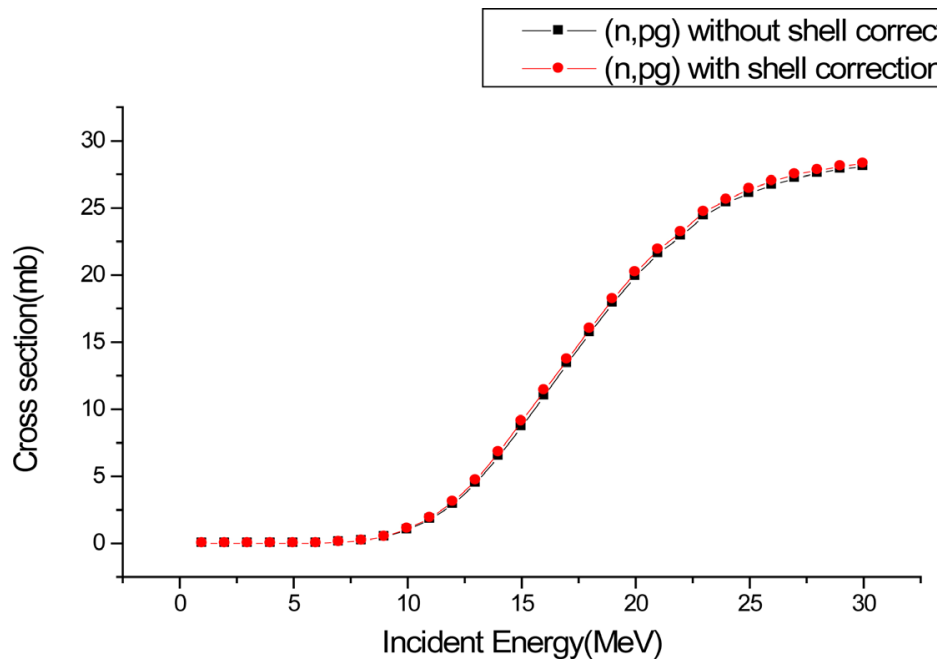

Figure 8. Excitation function of ${ }^{127} I(n, p g)$ reaction.

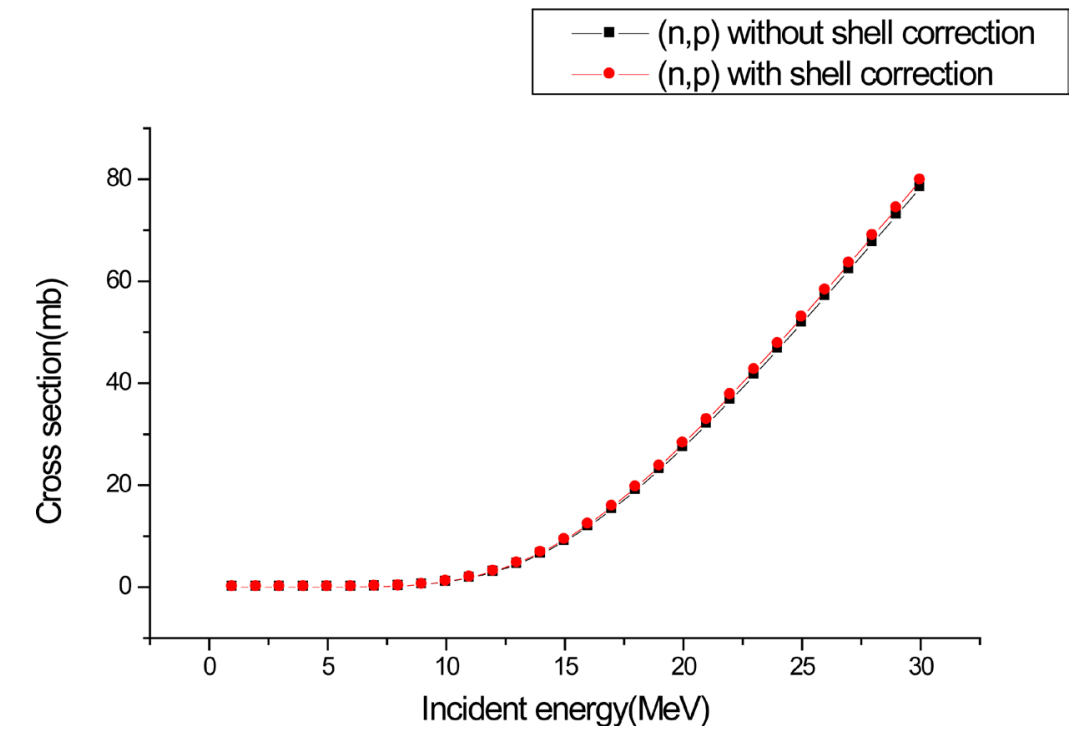

Figure 9. Excitation function of ${ }^{127} I(n, p)$ reaction. 


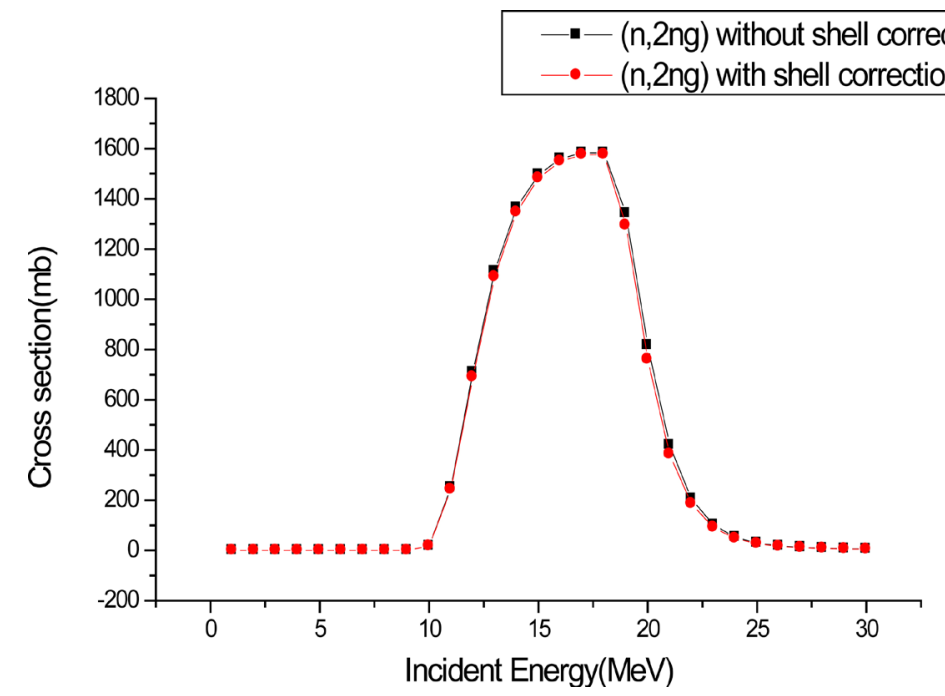

Figure 10. Excitation function of ${ }^{127} I(n, 2 n g)$ reaction.

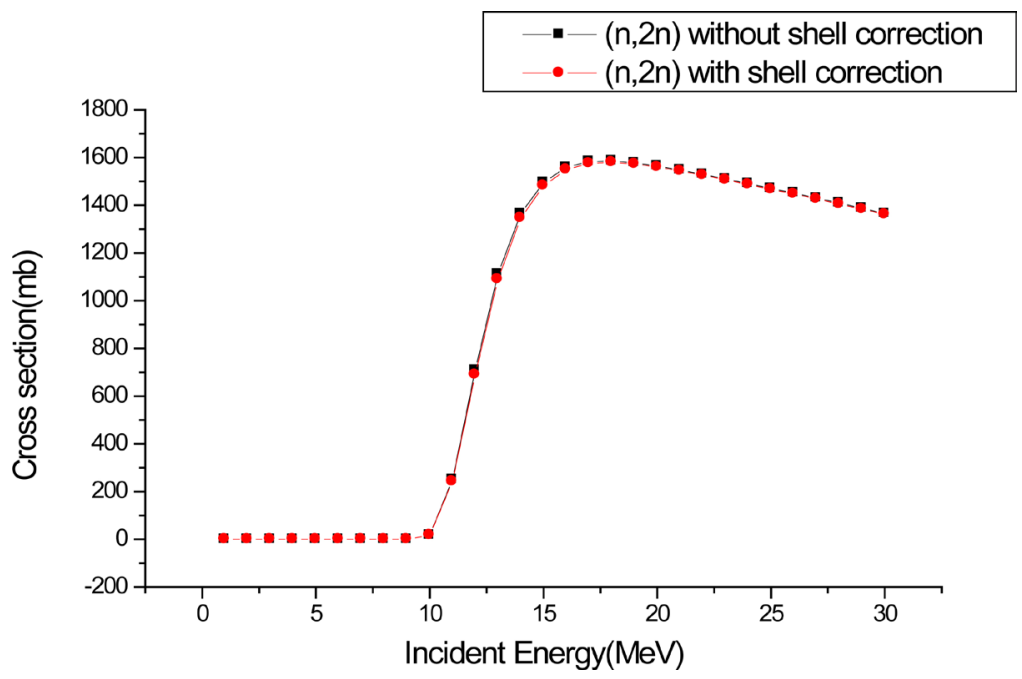

Figure 11. Excitation function of ${ }^{127} I(n, 2 n)$ reaction.

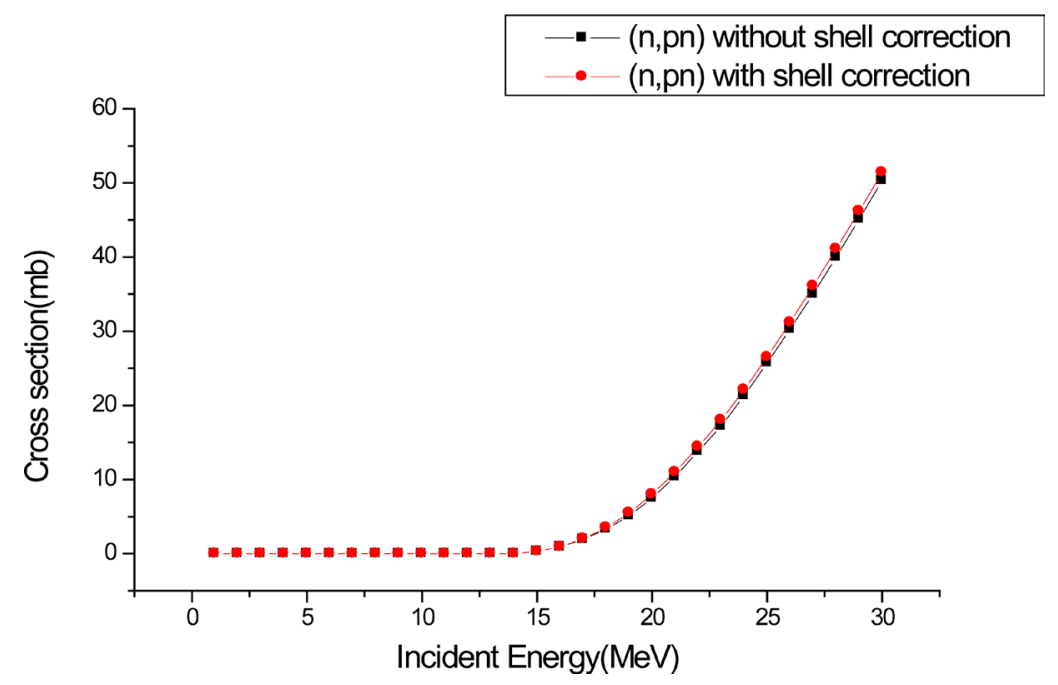

Figure 12. Excitation function of ${ }^{127} I(n, p n)$ reaction. 


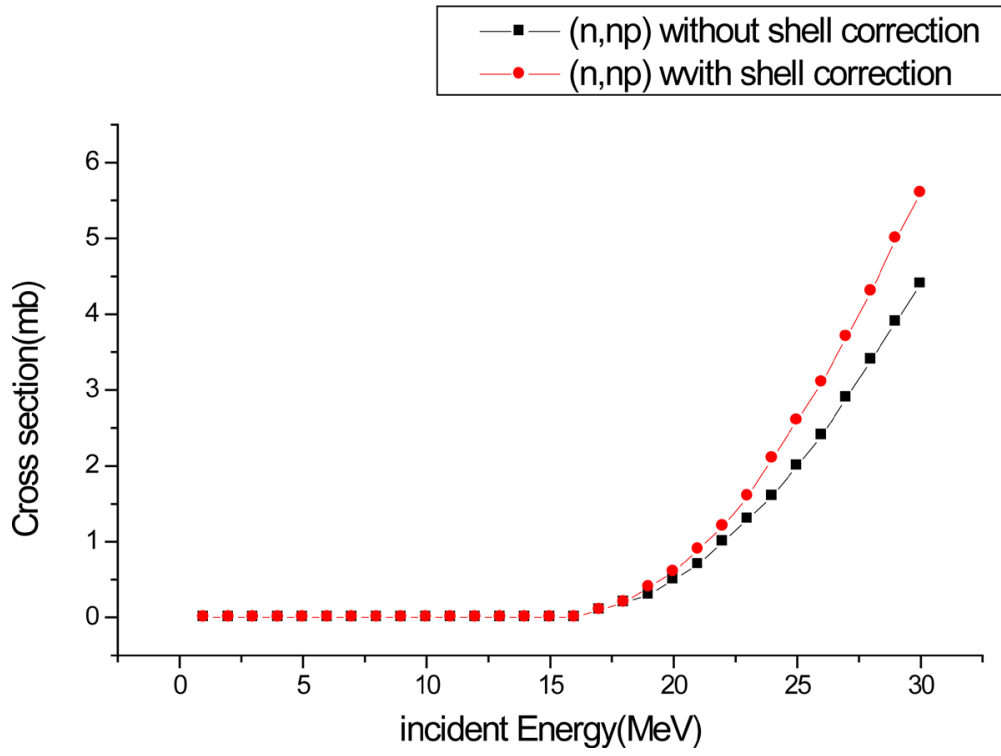

Figure 13. Excitation function of ${ }^{127} I(n, n p)$ reaction.

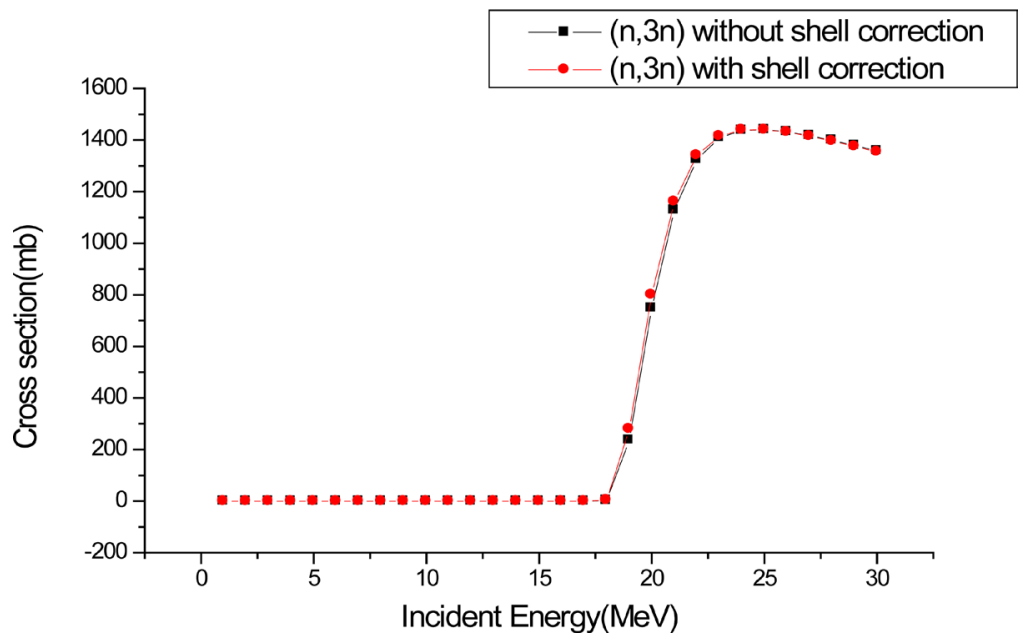

Figure 14. Excitation function of ${ }^{127} I(n, 3 n)$ reaction.

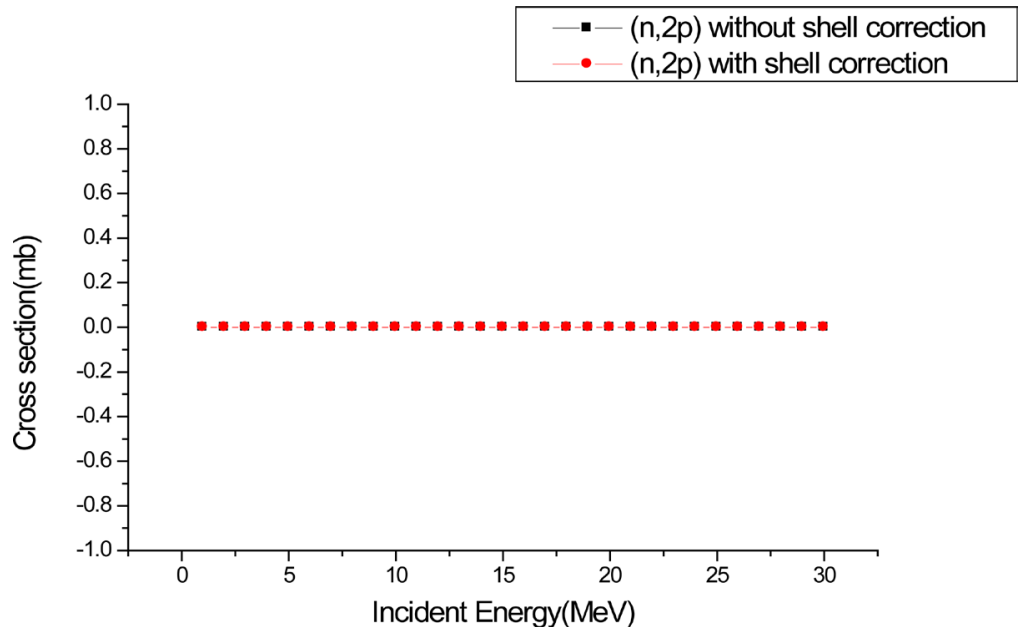

Figure 15. Excitation function of ${ }^{127} I(n, 2 p)$ reaction. 


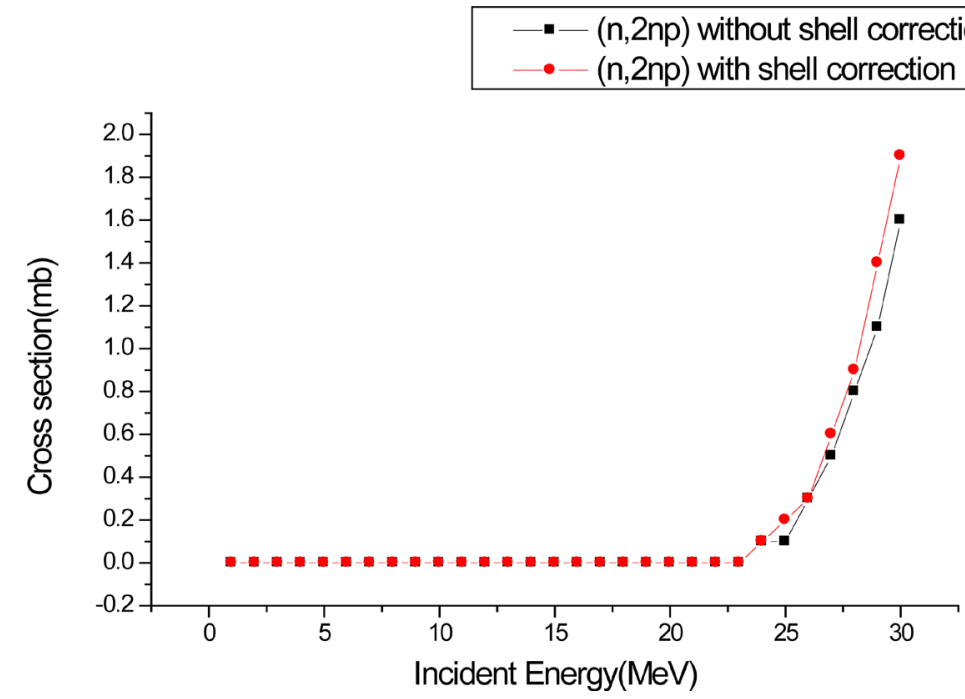

Figure 16. Excitation function of ${ }^{127} I(n, 2 n p)$ reaction.

Table 3. The correlation between different reaction charnels of Cross section without shell structure effect.

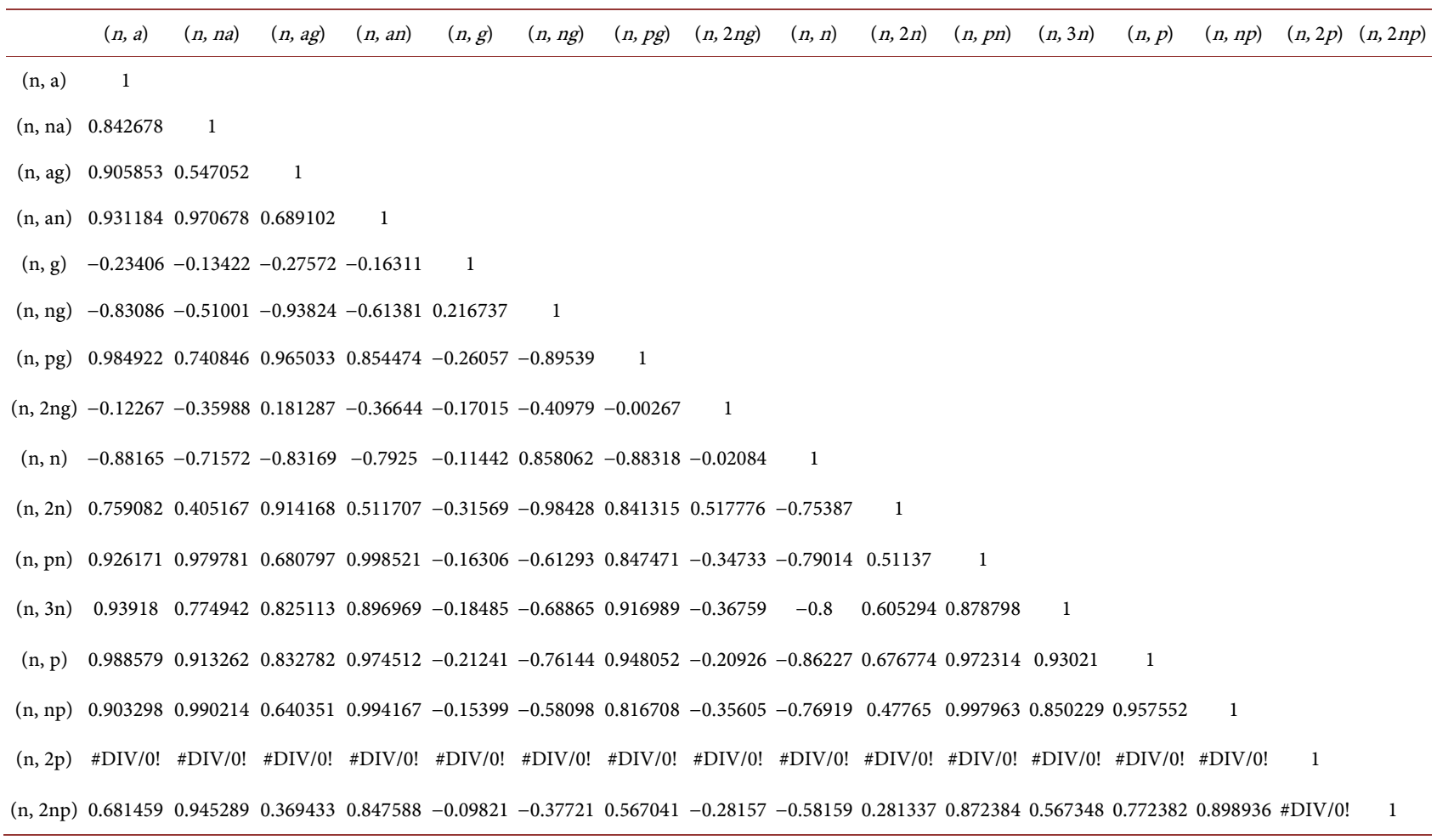

through gamma. The shell correction effect was considered and the results show no much difference observed.

Table 3 and Table 4 gives the correlation between exit charnels of the interaction of neutron at different energies with I-127 as a target, both Table 3 and Table 4 shown that the correlation between (n, 2p) charnel and other charnels is not defined, because the value of cross sections of $(n, 2 p)$ reaction is zero throughout the energy range considered from $0 \mathrm{MeV}$ to $30 \mathrm{MeV}$. This shows that this energy range is below the threshold energy for this reaction. 
Table 4. The correlation between different reaction charnels of Cross section with shell structure effect.

\begin{tabular}{|c|c|c|c|c|c|c|c|c|c|c|c|c|c|c|c|c|}
\hline & $(n, a)$ & $(n, n a)$ & $(n, a g)$ & $(n, a n)$ & $(n, g)$ & $(n, n g)$ & $(n, p g)$ & $(n, 2 n g)$ & $(n, n)$ & $(n, 2 n)$ & $(n, p n)$ & $(n, 3 n)$ & $(n, p)$ & $(n, n p)$ & $(n, 2 p)$ & $(n, 2 n p)$ \\
\hline$(\mathrm{n}, \mathrm{a})$ & 1 & & & & & & & & & & & & & & & \\
\hline$(\mathrm{n}, \mathrm{ag})$ & 0.905096 & 0.549077 & 1 & & & & & & & & & & & & & \\
\hline$(\mathrm{n}, \mathrm{an})$ & 0.930637 & 0.972695 & 0.686736 & 1 & & & & & & & & & & & & \\
\hline$(\mathrm{n}, \mathrm{g})$ & -0.23354 & -0.13438 & -0.27531 & -0.16238 & 1 & & & & & & & & & & & \\
\hline (n, ng) & -0.83517 & -0.51533 & -0.94249 & -0.61674 & 0.235641 & 1 & & & & & & & & & & \\
\hline$(\mathrm{n}, \mathrm{pg})$ & 0.983961 & 0.740888 & 0.965923 & 0.850868 & -0.26131 & -0.90238 & 1 & & & & & & & & & \\
\hline (n, 2ng) & -0.12549 & -0.36104 & 0.177819 & -0.36718 & -0.16769 & -0.40227 & -0.00033 & 1 & & & & & & & & \\
\hline$(\mathrm{n}, 2 \mathrm{n})$ & 0.763111 & 0.409918 & 0.918367 & 0.514298 & -0.31393 & -0.98624 & 0.848642 & 0.508476 & -0.78693 & 1 & & & & & & \\
\hline$(\mathrm{n}, \mathrm{pn})$ & 0.928438 & 0.979776 & 0.683906 & 0.998706 & -0.16345 & -0.61983 & 0.847872 & -0.34706 & -0.8107 & 0.518159 & 1 & & & & & \\
\hline$(n, 3 n)$ & 0.939159 & 0.773241 & 0.829076 & 0.891761 & -0.1854 & -0.69659 & 0.916915 & -0.36727 & -0.82078 & 0.614154 & 0.877458 & 1 & & & & \\
\hline$(\mathrm{n}, \mathrm{p})$ & 0.989003 & 0.91431 & 0.833487 & 0.973498 & -0.21246 & -0.76716 & 0.947318 & -0.20941 & -0.88598 & 0.682365 & 0.973022 & 0.928775 & 1 & & & \\
\hline$(\mathrm{n}, \mathrm{np})$ & 0.901491 & 0.991468 & 0.635552 & 0.994283 & -0.15259 & -0.58127 & 0.811293 & -0.35876 & -0.78476 & 0.477332 & 0.997344 & 0.844039 & 0.955514 & 1 & & \\
\hline$(\mathrm{n}, 2 \mathrm{p})$ & \#DIV/0! & \#DIV/0! & \#DIV/0! & \#DIV/0! & \#DIV/0! & \#DIV/0! & \#DIV/0! & \#DIV/0! & \#DIV/0! & \#DIV/0! & \#DIV/0! & \#DIV/0! & \#DIV/0! & \#DIV/0! & 1 & \\
\hline$(\mathrm{n}, 2 \mathrm{np})$ & 0.680139 & 0.941884 & 0.367921 & 0.846462 & -0.09775 & -0.37895 & 0.562994 & -0.27882 & -0.59244 & 0.282698 & 0.86827 & 0.560305 & 0.769782 & 0.897665 & \#DIV/0! & 1 \\
\hline
\end{tabular}

\section{Conclusions}

A nuclear reaction in the intermediate-energy region is a matter of interest in some fields of science and technology such as medical radionuclide production. Radioisotope production for nuclear medicine is important because of its common use in tomography devices. Both single photon emissions computed tomography (SPECT) and positron emission tomography (PET) are used for diagnosis in nuclear medicine. In the present work, we have investigated the excitation functions for the formation of ${ }^{128,127,126} \mathrm{I},{ }^{123,124,126} \mathrm{Sb},{ }^{127,126,125} \mathrm{Te}$ in the interactions of alpha particle with nucleus of iodine-127 isotope for the production of some medical radioisotopes.

The shell structure effects were considered and the statistical analysis shows that no significant change in the cross-section observed at the energy range from 0 - $30 \mathrm{MeV}$ considered.

This study shows that EXIFON code is a good tool for investigation of nuclear reaction cross section and this research work can be useful in the production of the radioisotopes of Iodine, Antimony and tellurium of high purity and in an efficient manner using cyclotron or nuclear reactors, these isotopes have potential application for field of medical science especially for therapeutic purposes embracing current and possible future needs.

\section{References}

[1] Art, O. and Aytekin, H. (2015) Calculation of Excitation Functions of Proton, Alpha and Deuteron Induced Reactions for Production of Medical Radioisotopes 
122-125I. Nuclear Instruments and Methods in Physics Research Section B: Beam Interactions with Materials and Atoms, 345, 1-8.

[2] Alharbi, A.A. and Azzam, A. (2012) Theoretical Calculations of the Reaction Cross-Sections for Proton-Induced Reactions on Natural Copper Using ALICE-IPPE Code. Applied Radiation and Isotopes, 70, 88-98.

https://doi.org/10.1016/j.apradiso.2011.09.009

[3] Skakun, Y. and Qaim, S.M. (2008) Measurement of Excitation Functions of Helion-Induced Reactions on Enriched Ru Targets for Production of Medically Important 103Pd and $101 \mathrm{mRh}$ and Some Other Radionuclides. Applied Radiation and Isotopes, 66, 653-667. https://doi.org/10.1016/j.apradiso.2007.11.013

[4] Qaim, S.M. (2004) Use of Cyclotrons in Medicine. Radiation Physics and Chemistry, 71, 917-926. https://doi.org/10.1016/j.radphyschem.2004.04.124

[5] Kalka, H. (1992) Hadrons and Nuclei Statistical Multistep Reactions from 1 to 100 MeV. Zeitschrift Physik a Hadron and Nuclei, 299, 289-299.

[6] Polster, D. and Kalka, H. (1991) Short Note Fission within a Statistical Multistep Model. Zeitschrift Physik a Hadron and Nuclei, 424, 423-424.

[7] Ahmad, I., Ibrahim, Y.Y. and Koki, F.S. (2017) Evaluation of Reaction Cross Section of Radionuclide by Particles Induced Nuclear Reactions Using EXIFON Code. Boson Journal of Modern Physics, 3, 236-244.

[8] Nesaraja, B.C., Linse, K., Spellerberg, S., Sudar, S., Suhaimi, A. and Qaim, S.M. (1999) Excitation Functions of Neutron Induced Reactions on Some Isotopes of Zinc, Gallium, and Germanium in the Energy Range of 6.2 to $12.4 \mathrm{MeV}$. Radiochimica Acta, 9, 1-9. https://doi.org/10.1524/ract.1999.86.12.1

[9] Ebiwonjumi, Y.E.C.B.F. (2014) Determination of Nuclear Reaction Cross-Sections for Neutron-Induced Reactions in Some Odd-A Nuclides. Advance in Physics Theories and Applications, 32, 55-69.

[10] Rao, A.V.M. and Rao, J.R. (1991) Pre-Equilibrium Analysis of the Excitation Functions of $(\mathrm{a}, \mathrm{xn})$ Reactions on Silver and Holmium. Il Nuovo Cimento A, 104, 863-874. https://doi.org/10.1007/BF02820560

[11] Muhammed, K., Onimisi, M.Y. and Jonah, S.A. (2011) Investigation of the Shell Effect on Neutron Induced Cross Section of Actinides. Journal of Nuclear and Particle Physics, 1, 6-9.

[12] Qaim, S.M. (1986) Recent Development in the Production of $18 \mathrm{~F}, 75,76,77 \mathrm{Br}$, and 123I. International Journal of Radiations and Instrumentation Part A. Applied Radiation and Isotopes, 37, 308-310.

[13] Watanabe, Y., Fukahori, T., Kosako, K., Shigyo, N., Murata, T., Yamano, N., Hino, T., Maki, K., Nakashima, H., Odano, N. and Chiba, S. (2005) Nuclear Data Evaluations for JENDL High-Energy File. International Conference on Nuclear Data for Science and Technology, 326-331. https://doi.org/10.1063/1.1945015

[14] Ford, H. (2012) Radiation Safety Information Computational Center Changes to the Rsicc Code and Lawrence Livermore National Laboratory, Liver-More, 1-13.

[15] White, J.E., Manneschmidt, J.B., Finch, S.Y. and Dickens, J.K. (1997) Abstracts of Computer Programs and Data Libraries Pertaining to Photon Production Data. Computational Physics and Engineering Division, 32, 101-103.

[16] Yamoah, S. and Asamoah, M. (2013) Calculations of Excitation Functions of (n, p), $(\mathrm{n}, \mathrm{a})$ and $(\mathrm{n}, 2 \mathrm{n})$ Reaction Cross-Sections for Stable Isotopes of from Reaction Threshold to $20 \mathrm{MeV}$. Optics Communication, 3, 100-107. 
Submit or recommend next manuscript to SCIRP and we will provide best service for you:

Accepting pre-submission inquiries through Email, Facebook, LinkedIn, Twitter, etc. A wide selection of journals (inclusive of 9 subjects, more than 200 journals)

Providing 24-hour high-quality service

User-friendly online submission system

Fair and swift peer-review system

Efficient typesetting and proofreading procedure

Display of the result of downloads and visits, as well as the number of cited articles Maximum dissemination of your research work

Submit your manuscript at: http://papersubmission.scirp.org/

Or contact ijmpcero@scirp.org 